\title{
MENTORING ON SCIENCE TEACHER EDUCATION IN RUSSIA AND INTERNATIONAL PERSPECTIVES
}

\author{
Muhammet Usak, Alfiya R. Masalimova \\ Kazan Federal University, Russia
}

Nowadays, mentoring as an educational form of Russia's occupational activity is undergoing fundamental changes due to the variety of interrelated factors affecting the mentoring system. The requirements for the mentoring system itself are affected by these changes as well. Nature of the mentoring activity influences socio-economic, political, socio-cultural, pedagogical, methodical and individual factors. Socio-economic factors that determine not only the enterprises' state order, but also modern educational institutions' order to revive and improve the traditions of mentoring receive the highest priority among these factors (Antipin, 2011).

Mentoring is one of the forms of training in the process of occupational activity of a novice teacher, aimed at the development of his/her applied occupational competencies and the disclosure of their potential to determine the vectors of teachers' individual professional development (Charina, 2004; Chernikova, 2013; Masalimova, 2013). The effectiveness of the mentorship stems from the fact that the external training of teachers (refresher courses, internships) does not take into account the characteristics of a specific educational institution. Therefore, any educational institution should prepare mentors within their teaching staff, who will train young novice teachers taking into account the established traditions and values of this institution.

The mentoring process affects the interests of at least three interactive entities: a new teacher, a mentor/mentor teacher and an educational institution (du Plessis, 2016; Hudson, Usak, \& Savran-Gencer, 2010; Jung \& Nam, 2018). The novice teacher acquires professional knowledge, skills and abilities, improves his/her professional skills and abilities; builds a professional career; learns to construct relationships with mentors, which will then help to do it with the environment of the institution in which he/she will adapt; receives data about the traditions, values and norms of the educational institution, in which he/she carries his/her occupational activities. As far as the mentor is concerned, he also improves his professional and commercial qualifications and pedagogical skills in the mentoring process. Likewise, the educational institution increases the level of cultural and vocational education of its staff; strengthens relationships between employees; ensures continuity of the mentoring corps.

Modern mentorship in the Russian concept is based on the following regulatory norms or principles:

- the principle of occupational and mentoring activities' integration not only allows mentors to optimize the process of acquisition of occupational competencies, but also the interprofessional competencies that contribute to the transfer of occupational experience to young staff and the accumulation of the organization's collective knowledge.

- the principle of tradition-based nature and innovation, which implies, on the one hand, reliance on already established traditional ideas, concepts and mentoring experience, and on the other - constant updating of its content and technologies in accordance with the latest developments in science and technology. The choice of this principle stems from the fact that mentors' adherence to traditional teaching meth- 
ISSN 1648-3898/Print/

ISSN 2538-7138/Online/

ods only, which are usually reproductive in nature, do not direct young teachers to the formulation and resolution of creative tasks under the updated production conditions. Such a lack of mentors' training to innovative changes in the content and technologies of young personnel's training hinders the process of their training and adaptation to occupational activities, which adversely affects the strategic objectives of modern educational institution.

- the principle of outstripping training, involving advanced entry into mentoring activities, namely the formation of positive motivation, value attitude to mentoring, psychological, pedagogical and methodical competencies of the modern mentor.

The main mechanism for the implementation of the proposed principles of mentoring is an integrative approach, involving the integration and interaction of 1) two processes - the process of occupational development of teachers and their readiness to implement mentoring activities; 2 ) two types of activities - occupational and mentoring; 3 ) all entities of the educational institution in the process of mentoring.

When it comes to international practice in the field of mentoring, it should be noted that there are different perspectives on the concept of mentoring. This is due to two different theoretical concepts: North American and European one.

The interpretation of the North American concept sees the mentor as a senior and more authoritative person expecting dedication in response to his/her helpful advice, wise guidance and help (Roberts, 2000; Zachary, 2005, 2009). Within this personification, a mentor can be attributed as a direct supervisor or as a person's department manager, and these are relationships in which the term protégé can be applied to identify them. In this case, a mentor is more interested in promoting his/her mentee than providing effective leadership in learning. Thus, mentoring seems to have essential attributes: a process; a supportive relationship; assistance process; a teachinglearning process; a reflective process; a career development process; a formalized process; and a role constructed by mentor or for a mentor. Coaching, sponsorship, role modeling, evaluation and an informal process appear to be conditional features of mentoring as a phenomenon (Roberts, 2000).

On the other hand, the interpretation of the European mentoring suggests that a mentor has a lot of practical experience rather than ability to promote the mentee. One of the characteristics of an effective mentoring relationship is an open collar dialogue, i.e. avoiding significant differences in the relationship so that both parties are on an equal footing (Cain, 2009; Colvin \& Ashman, 2010; Peterson et al., 2010). As a result, European mentors are usually independent in their decisions, mainly because it is very difficult for anyone to open up to someone who can influence their salary, status and overall well-being. The main purpose of business relations is education and development, although the outcomes may be closely associated with the development of the mentee's ability to manage his/her career.

Compared to national experience, the mentoring activity in international corporate training practice is closely related to the use of technologies intended to transfer professional experience to novice teachers, to develop their professional qualifications, as well as to identify and develop their potential. In the international mentoring practice, there may be categories such as mentoring (targeted experience transfer), coaching (explaining the potential of the student's personality), e-coaching (online coaching), tutoring (accompanying the learning process, discussion of the experience of knowledge transfer into real practice), shadowing (monitoring of the work process), supervision (monitoring of the occupational activities of the novice worker and evaluation of the level of formation of competences) (Hudson, Usak, \& Savran-Gencer, 2010; Schmidt, 2008; Tillema, Smith, \& Leshem, 2011; Yavuz, 2011).

Among the most common forms and methods used in mentoring activities abroad, we can distinguish: budding (involving the student in another's activity), business simulations (corporate management simulation), storytelling (telling of stories), etc. (Masalimova, Usak, \& Shaidullina, 2016; Masalimova \& Shaidullina, 2016).

Under the conditions of the modern Russian mentoring system, this form of vocational training is strictly integrated with the international technologies offered, taking into account the existing Russian mentoring traditions, the realities and requirements of modern educational institutions.

\section{Acknowledgements}

The work is conducted according to the Russian Government Program of Competitive Growth of Kazan Federal University. 


\section{References}

Antipin, S. G. (2011). Traditions of mentoring in the history of national education (PhD Thesis). Nizhny Novgorod.

Cain, T. (2009). Mentoring trainee teachers: How can mentors use research? Mentoring \& Tutoring Partnership in Learning, 17(1), 53-66. https://doi.org/10.1080/13611260802233498.

Charina, Ye. V. (2004). Relations in the system "mentor-young specialist" in the process of professionalization (PhD Thesis). Moscow.

Chernikova, Ye. A. (2013). Mentoring as a means of accompanying the professional-personal development of a social service specialist (PhD Thesis). Volgograd.

Colvin, J. W., \& Ashman, M. (2010). Roles, risks, and benefits of peer mentoring relationships in higher education. Mentoring \& Tutoring Partnership in Learning, 18(2), 121-134. https://doi.org/10.1080/13611261003678879.

du Plessis, A. (2016). Student-teachers' pedagogical beliefs: Learner-centred or teacher-centred when using ICT in the science classroom? Journal of Baltic Science Education, 15(2), 140-158.

Hudson, P., Usak, M., \& Savran-Gencer, A. (2009). Employing the five-factor mentoring instrument: Analysing mentoring practices for teaching primary science. European Journal of Teacher Education, 32(1), 63-74.

Hudson, P., Usak, M., \& Savran-Gencer, A. (2010). Benchmarking Mentoring Practices: A Case Study in Turkey. Eurasia Journal of Mathematics, Science \& Technology Education, 6(4), 245-252. https://doi.org/10.12973/ejmste/75245

Jung, D., \& Nam, J. (2018). Analysis of mentor teachers'mentoring type and type changes in collaborative mentoring programs for professional development of beginning science teachers' teaching practice. Journal of the Korean Chemical Society-Daehan Hwahak Hoe Jee, 62(6), 441-452. HTTPS://DOI.ORG/10.5012/JKCS.2018.62.6.441.

Masalimova, A. R. (2013). Corporate training for mentors: Priority approaches. World of Science, Culture, Education, 4(41), 96-99.

Masalimova, A. R., \& Shaidullina, A. R. (2016). Study of international mentoring and coaching practices and their constructive application in the Russian system of corporate education and training. International Journal of Environmental and Science Education, 11(8), 1797-1806.

Masalimova, A. R., Usak, M., \& Shaidullina, A. R. (2016). Advantages and disadvantages of national and international corporate training techniques in adult education. Current Science, 111(9), 1480-1485. https://doi.org/10.18520/CS/V111/l9/1480-1485.

Peterson, S. M., Valk, C., Baker, A. C., Brugger L., \& Hightower, A. D. (2010). “We're not just interested in the work": Social and emotional aspects of early educator mentoring relationships. Mentoring \& Tutoring Partnership in Learning, 18(2), 155-175. https://doi.org/10.1080/13611261003678895

Roberts, A. (2000). Mentoring revisited a phenomenological reading of the literature. Mentoring \& Tutoring Partnership in Learning, 8(2), 145-170. https://doi.org/10.1080/713685524.

Schmidt, M. (2008). Mentoring and being mentored: The story of a novice music teacher's success. Teaching and Teacher Education, 24(3), 635-648. https://doi.org/10.1016/j.tate.2006.11.015.

Tillema, H. H., Smith, K., \& Leshem, S. (2011). Dual roles - conflicting purposes: A comparative study on perceptions on assessment in mentoring relations during practicum. European Journal of Teacher Education, 34(2), 139-159. https://doi.org/10. 1080/02619768.2010.543672.

Yavuz, A. (2011). The problematic context of mentoring: Evidence from an English language-teaching department at a Turkish University. European Journal of Teacher Education, 34(1), 43-59. https://doi.org/10.1080/02619768.2010.516431.

Zachary, L. J. (2005). Creating a mentoring culture: The organization's guide. San Francisco, CA: Jossey-Bass.

Zachary, L. J. (2009). The mentee's guide: Making mentoring work for you. San Francisco, CA: Jossey-Bass.

\section{Muhammet Usak}

Alfiya R. Masalimova
PhD, Associate Professor, Institute of Pedagogy and Psychology, Kazan Federal University, 1 Mezhlauk St., Kazan, 420021, Russia. E-mail: musaktr@gmail.com Website: https://orcid.org/0000-0002-6537-9993

PhD, Associate Professor, Institute of Pedagogy and Psychology, Kazan Federal University, 1 Mezhlauk St., Kazan, 420021, Russia. Website: https://www.researchgate.net/profile/Alfiya_ Masalimova2 